JURNAL INFORMATIKA Vol. 11, No. 2 Juli 2017

\title{
PENGEMBANGAN SISTEM INFORMASI GEOGRAFIS BERBASIS NODE.JS UNTUK PEMETAAN MESIN DAN TRACKING ENGINEER DENGAN PEMANFAATAN GEOLOCATION PADA PT IBM INDONESIA
}

\author{
Rachmat Fajrin \\ Teknik Informatika dan Komputer/Teknik Informatika, Politeknik Negeri Jakarta \\ J1. Prof. Dr. G. A. Siwabessy, Kampus Baru UI, Beji, Kukusan, Kota Depok, Jawa \\ Barat, 16424, Indonesia \\ Email :rachmatfajrin@gmail.com
}

\begin{abstract}
Abstrak
PT IBM memiliki banyak klien di Indonesia, ini membuat persebaran produk (dalam hal ini mesin atm) yang semakin meluas di wilayah Indonesia. Hal ini memicu PT IBM untuk menempatkan engineer dibanyak wilayah untuk memenuhi kebutuhan services dan maintenance. Untuk itu dalam penelitian ini dikembangkan sebuah sistem informasi geografis untuk pemetaan mesin dan tracking engineer dengan pemanfaatan geolocation yang bertujuan untuk menampilkan peta digital beserta lokasi mesin dan engineer di seluruh Indonesia, yang akan memudahkan PT IBM dalam pemberian tugas kepada engineer untuk services dan maintenance ke lokasi mesin terdekat. Sistem ini dibangun menggunakan beberapa software open source yaitu, Node.JS dan Express.JS yang merupakan server-side javascript web platform, Handlebars untuk template engine, MySQL sebagai database storage, Postman yang berfungsi sebagai API (Application Program Interface) testing, Google Maps API untuk implementasi peta digital dan juga Firebase Cloud Messaging (FCM) untuk platform mengirim notifikasi dari web ke device engineer.
\end{abstract}

Keywords: sistem informasi geografis (SIG) berbasis web, geolocation, node.js, pemetaan, tracking, google maps, firebase cloud messaging

\section{PENDAHULUAN}

PT IBM Indonesia merupakan salah satu perpanjangan IBM (International Business Machines) Corporation, yang beroperasi di Indonesia sejak tahun 1937. PT IBM Indonesia merupakan perusahaan yang bergerak dibidang information technology dan services terutama mendukung kinerja bisnis dari sebuah perusahaan. Dengan terus bertambahnya klien PT IBM di Indonesia, peta persebaran produk (dalam hal ini mesin atm) juga semakin luas, hal ini memicu PT IBM untuk menempatkan banyak engineer di wilayah yang strategis agar dapat mengakomodasi services dan maintenance untuk klien yang merupakan salah satu jasa unggulan PT IBM Indonesia. Untuk memudahkan pemberian tugas kepada engineer jika ada services dan maintenance yang dibutuhkan klien, maka dikembangkan sebuah aplikasi berbasis Sistem Informasi Geografis (SIG) dengan tujuan untuk memetakan lokasi mesin dan tracking engineer. Sistem ini akan mengimplementasikan peta digital untuk memvisualisasikan lokasi mesin dan juga engineer, sedangkan data geolocation yang digunakan didapat dari mobile device yang mengkonsumsi API (Application Program Interface) yang disediakan dari Sistem Informasi Geografis. 


\section{JURNAL INFORMATIKA Vol. 11, No. 2 Juli 2017}

Sistem Informasi Geografis berbasis web sendiri merupakan sebuah sistem yang mempunyai data spasial atau koordinat yang kemudian diolah menjadi informasi dan pemetaan. Kemampuan dasar Sistem Informasi Geografis yaitu mengintegrasikan berbagai operasi basis data seperti query, menganalisisnya serta menampilkannya dalam bentuk pemetaan berdasarkan letak geografisnya. Inilah yang membedakan SIG dengan sistem informasi lain.

\section{TINJAUAN PUSTAKA}

\subsection{Metode Sekuensial Linier}

Metode yang digunakan dalam pengembangan sistem aplikasi ini adalah metode sekuensial linier, sering juga disebut waterfall.Model sekuensial linier menyediakan pendekatan alur hidup perangkat lunak secara sekuensial atau urut dimulai dari analisis, desain, pengkodean, pengujian dan tahap support. Berikut adalah gambar model sekuensial linier :

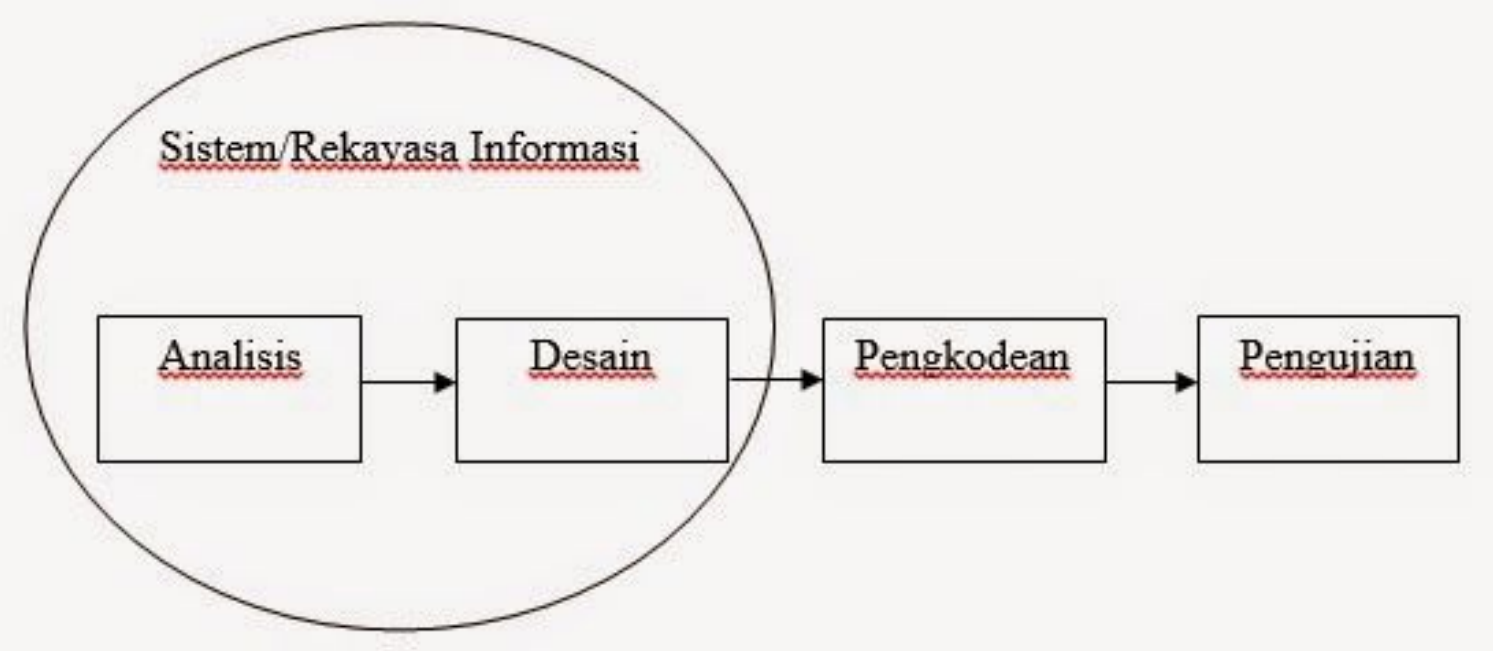

Gambar 4.Illustrasi Model Sekuensial Linier

\subsection{Sistem Informasi Geografis}

Sistem informasi geografis adalah suatu sistem berbasis komputer untuk menangkap, menyimpan, mengecek, mengintegrasikan, memanipulasi dan menampilkan data dengan peta digital.

\subsection{Node.JS}

Node.JS adalah sistem perangkat lunak yang didesain untuk pengembangan aplikasi web.Node.JS dapat juga disebut sebagai runtime environment.Aplikasi ini ditulis dalam campuran Bahasa $\mathrm{C}++$ dan juga JavaScript, mempunyai model event driven (basis event) dan asynchrounous I/O. Tidak seperti kebanyakan bahasa JavaScript yang dijalankan pada web browser, Node.JS dieksekusi sebagai aplikasi server.Node.JS dapat berjalan di server karena dukungan dari V8 Engine buatan Google dan beberapa modul bawaan yang terintegrasi seperti modul http, modul filesystem, modul security dan beberapa modul penting lainnya.

\subsection{Express.JS}

Express.JS merupakan sebuah Node.JS framework yang berguna untuk mempermudah pembuatan aplikasi berbasis Node.JS dengan menggunakan design pattern yang dapat disesuaikan dan sangat fleksibel. Selain itu Express.JS juga 


\section{JURNAL INFORMATIKA Vol. 11, No. 2 Juli 2017}

merupakan framework yang sangat ringan dan cocok untuk membuat web aplikasi dan API.

\subsection{Handlebars}

Handlebars merupakan salah satu template engine yang populer digunakan dalam pengembangan aplikasi web.Fungsi handlebars adalah menghasilkan dokumen dari template dan data.

\subsection{MySQL}

MySQL adalah Relational Database Management System (RDBMS) yang didistribusikan secara gratis dibawah GPL (General Public License).Sedangkan SQL (Structured Query Language) sendiri adalah sebuah konsep pengoperasian database untuk pemilihan / seleksi dan pemasukan data. Keandalan suatu database system (DBMS) dapat diketahui dari cara kerja optimasi dalam melakukan proses perintah SQL yang dibuat pengguna maupun program - program aplikasi lainnya.

\subsection{Postman}

Postman merupakan sebuah REST client berbasis web yang tersedia dalam bentuk ekstensi pada Google Chrome. Postman mempunyai tampilan antarmuka (user interface) yang baik dan juga lengkap. Postman mempunyai fitur seperti design, build, test dan documentation API.

\subsection{Google Maps API}

Google Maps API adalah suatu library yang berbentuk Javascript.Cara membuat Google Maps untuk ditampilkan pada suatu web atau mobile membutuhkan pengetahuan mengenai HTML serta Javascript, serta koneksi internet yang sangat stabil.Dengan menggunakan Google Maps API, dapat menghemat waktu dan biaya untuk membangun aplikasi peta digital yang handal, sehingga programmer dapat fokus dengan data - data yang ditampilkan.

\subsection{Firebase Cloud Messaging (FCM)}

FCM merupakan proyek yang dikembangkan oleh Google Inc. FCM berfungsi untuk menyampaikan informasi berupa pesan (notification message) ke perangkat mobile Android [5].FCM memberikan kemudahan dalam menyampaikan pesan secara gratis tidak terikat besarnya suatu pesan. FCM services akan mengatur setiap pesan yang dikirim agar sesuai dengan perangkat mobile tujuan pesan (receiver).

\section{Desain Sistem}

\subsection{Arsitektur Sistem}

Arsitektur sistem dapat digambarkan sebagai berikut : 
JURNAL INFORMATIKA Vol. 11, No. 2 Juli 2017

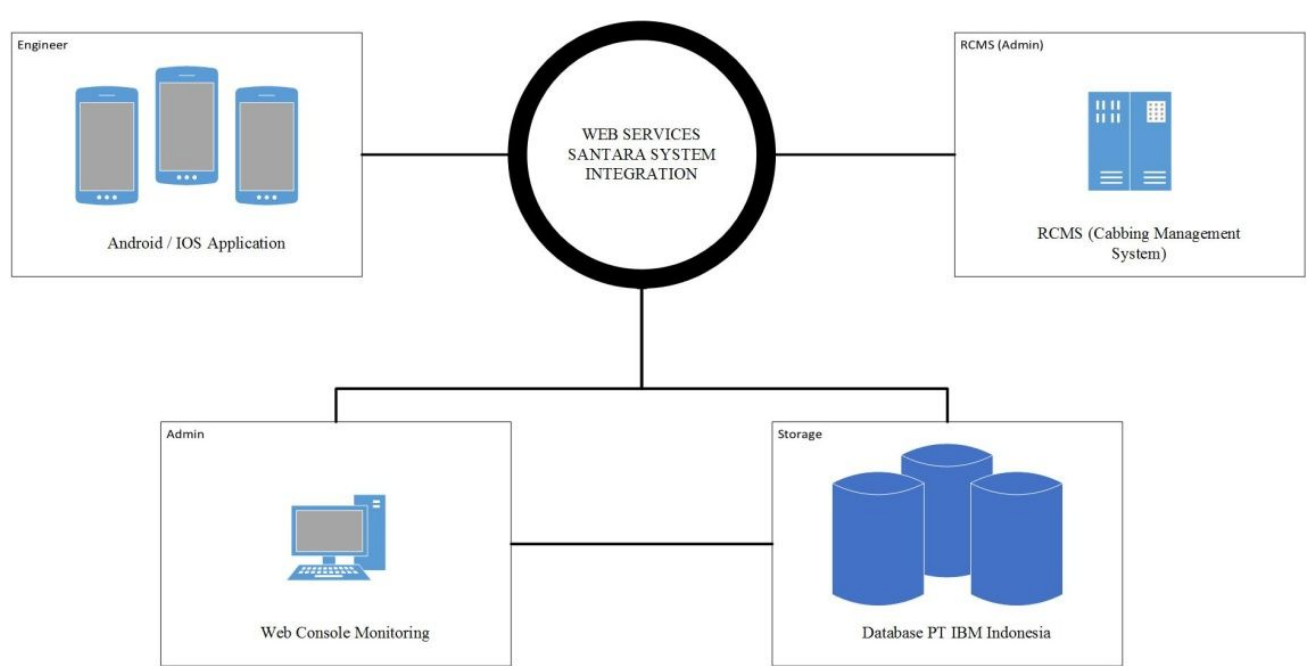

Gambar 2.Illustrasi Arsitektur Sistem

Gambar 2 menunjukkan illustrasi arsitektur sistem secara keseluruhan.Pada gambar tersebut, komponen Web Services Santara System Integration, Database dan Web Console Monitoring termasuk kedalam Sistem Informasi Geografis berbasis web.

\subsection{Flowchart Sistem}

Flowchart sistem dapat digambarkan sebagai berikut : 


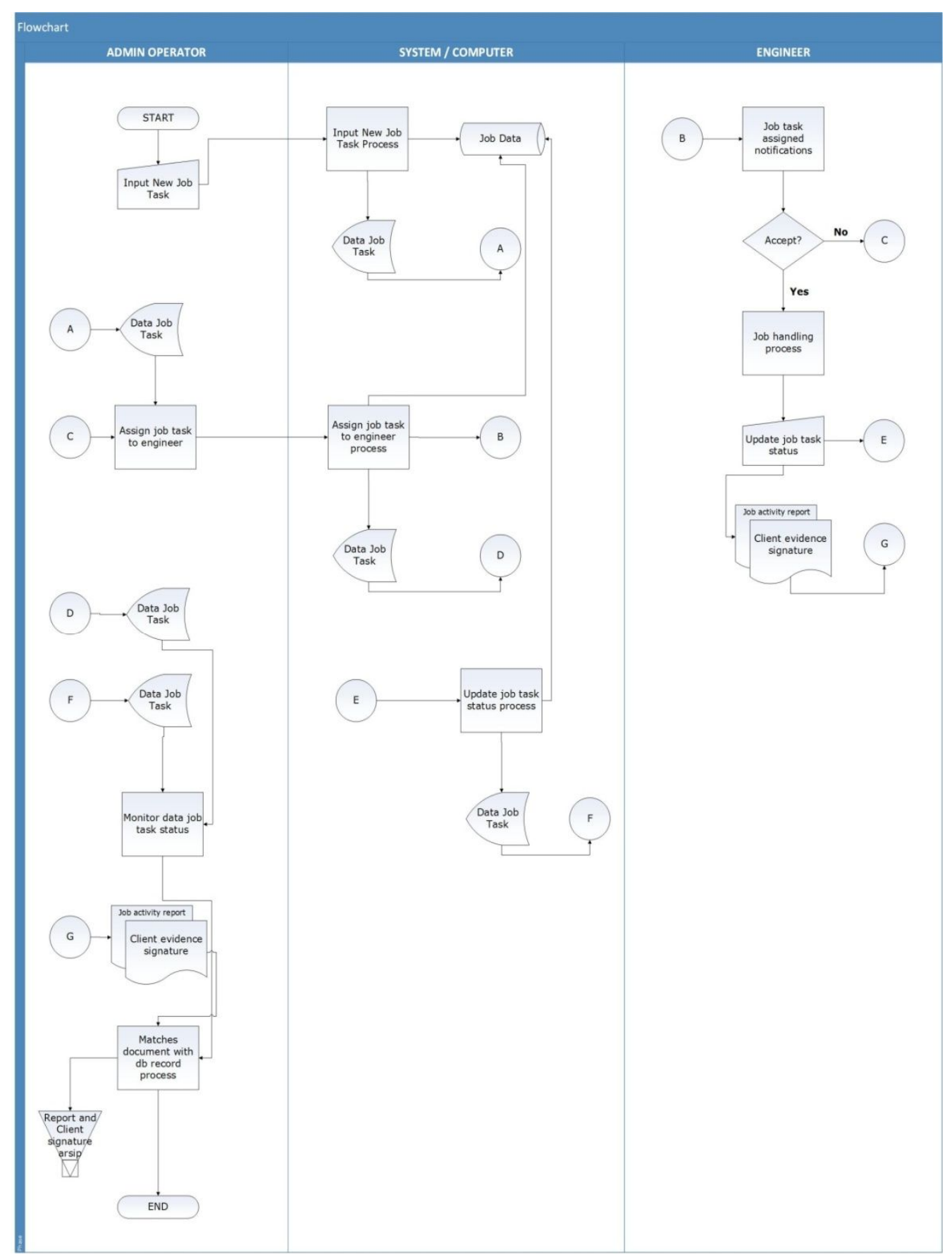

Gambar 3.Flowchart Sistem

Gambar 3 menjelaskan tentang rancangan alur data yang dimulai dari admin sampai kepada engineer. Admin bertugas untuk memberikan tugas kepada engineer yang kemudian akan mengirim notifikasi ke device engineer, dalam pengerjaantugas, engineer akan melakukan partial update ke dalam sistem sampai tugas tersebut selesai.

\section{IMPLEMENTASI DAN HASIL}

Sistem informasi geografis berbasis web ini terdiri menu assign job task yang berisi peta digital (maps) dan juga pin yang menandakan lokasi mesin dan engineer dan menu view job task. Berikut merupakan screenshot aplikasi sistem informasi geografis. 


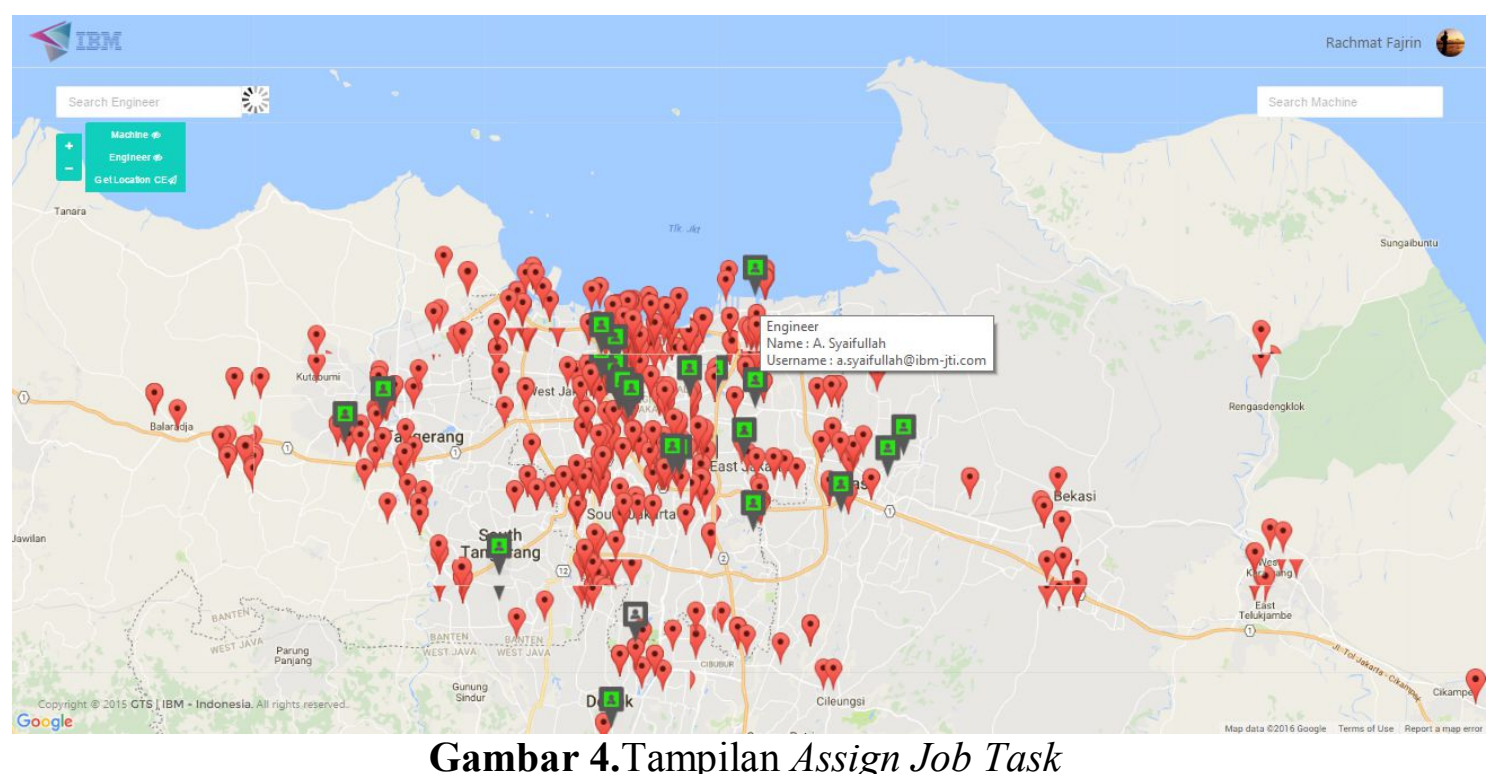

Gambar 4.Tampilan Assign Job Task

Gambar 4 merupakan tampilan awal menu assign job task, admin dapat melihat peta persebaran mesin atm di wilayah DKI Jakarta, dan juga lokasi para engineer.

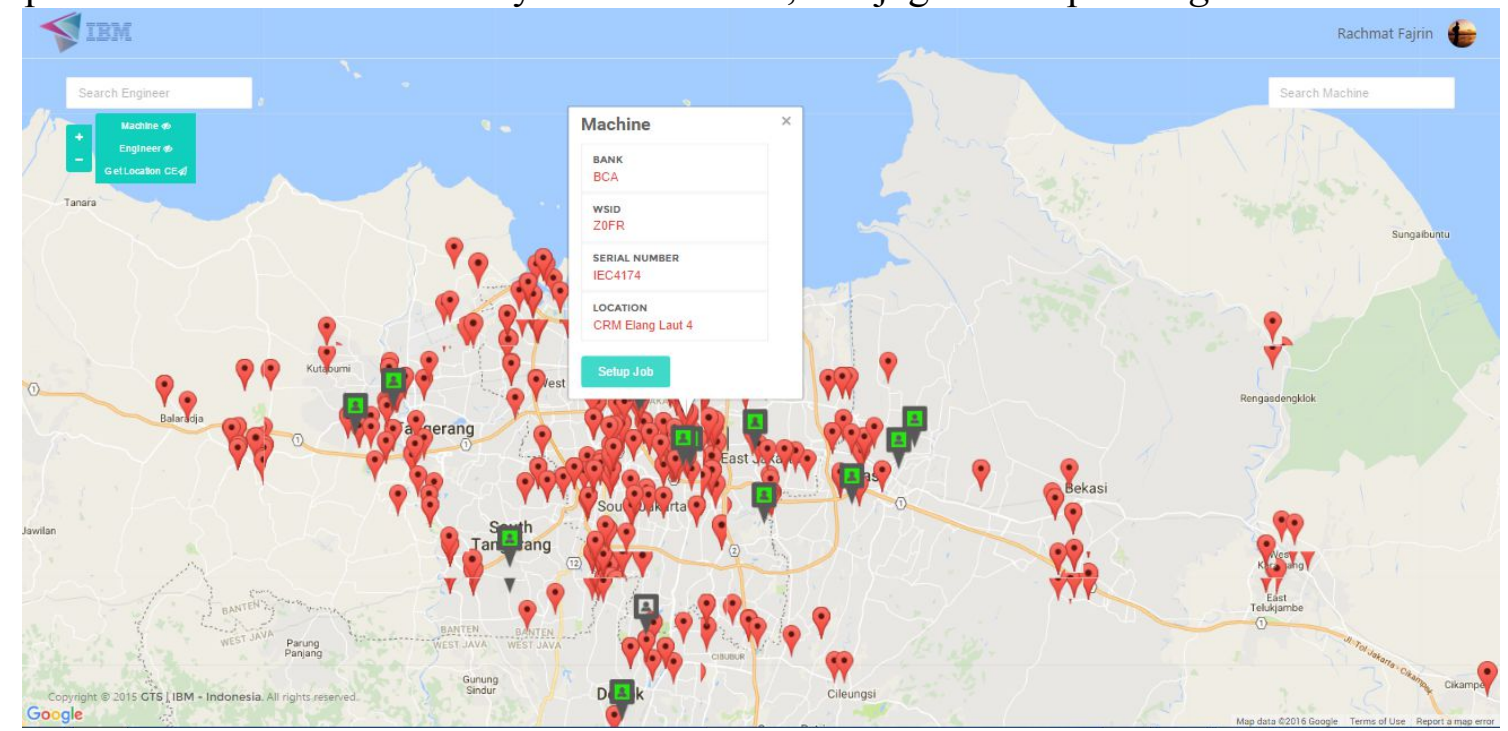

Gambar 5.Tampilan Popup Setup Job

Gambar 4 menunjukkan tampilan ketika pin mesin diklik, maka akan muncul popup yang berisikan informasi untuk membuat sebuat tugas (task) yang akan diberikan kepada engineer. 


\section{JURNAL INFORMATIKA Vol. 11, No. 2 Juli 2017}

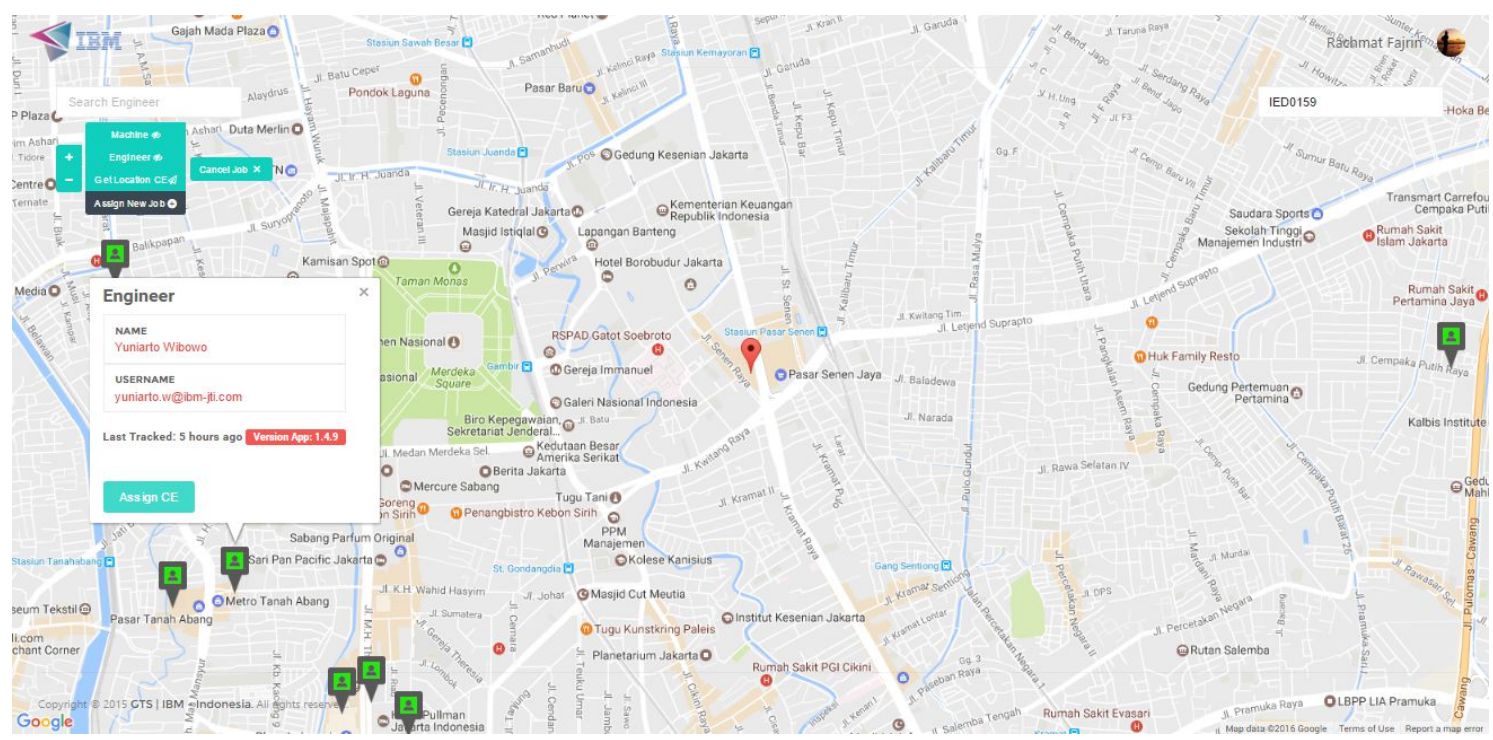

Gambar 6.Tampilan Popup Assign Engineer

Gambar 6 merupakan tampilan setelah admin memilih engineer, akan muncul popup yang berisikan informasi terkait engineer seperti nama dan username dan juga waktu tracking terakhir. Pada popup ini, setelah admin klik Assign CE, maka notifikasi akan sampai ke device engineer.

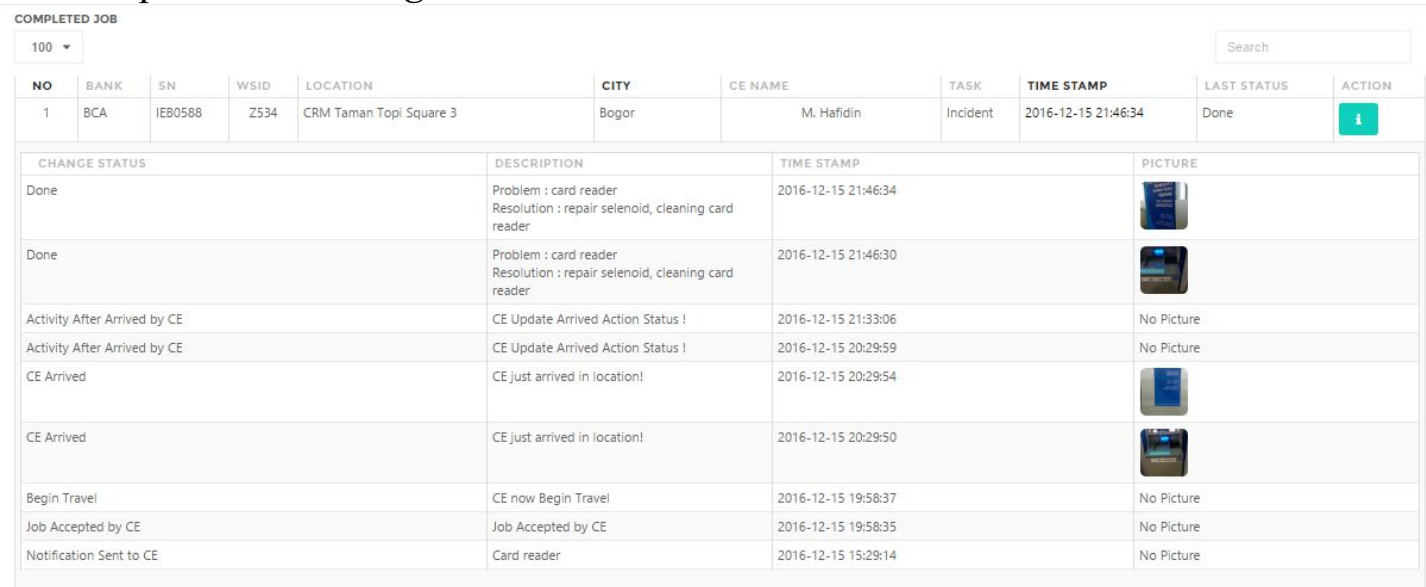

Gambar 7.Tampilan View Job Task

Gambar 7 menunjukkan hasil dari partial update yang dilakukan engineer saat sedang mengerjakan tugas yang diberikan admin. Partial update dilakukan dengan skema device engineer mengonsumsi API yang telah dibuat Sistem informasi Geografis berbasis web.

\section{KESIMPULAN}

Berdasarkan penelitian yang telah dilakukan maka dapat disimpulkan sistem yang dibangun berupa Sistem Informasi Geografis berbasis web dapat berjalan dengan baik, selain itu sistem juga terstruktur dan dapat memetakan lokasi mesin dan tracking engineer dengan pemanfaatan geolocation. 
JURNAL INFORMATIKA Vol. 11, No. 2 Juli 2017

\section{REFERENSI}

a. Bohrer, S., Zielke, T., \& Freiburg, V. (1995), "Integrated obstacle detection framework for intelligent cruise control on motorways", makalah presentasi pada IEEE Intelligent Vehicles Symposium. Detroit, MI: Piscataway.

b. Prahasta, Eddy. (2001), "Konsep-konsep Dasar Sistem Informasi Geografis", Bandung: Informatika.

c. Rosa, A.S dan Salahuddin, M. (2011), "Modul Pembelajaran Rekayasa Perangkat Lunak (Terstruktur dan Berorientasi Objek)", Bandung: Modula.

d. Turban, Efrain. (2005), "Decision Support System and Intelligent System", Yogyakarta: Andi.

e. Kurniawan, Rulianto. (2010), "PHP \& MySQL untuk Orang Awam", Palembang: Maxikom.

f. Google Inc, https:/firebase.google.com/docs/cloud-messaging/ (diakses tanggal 16 Desember 2016) 